\title{
O PÁTIO do COLÉGIO EM SÃo PAULO ENTRE 1889 A 1972: AGENTES, TENSÕES E REPRESENTAÇÕES
}

\section{The Jesuit College In São Paulo (1889-1972): Social Actors, Tensions, Representations}

\author{
João Carlos Santos Kuhn \\ Faculdade de Arquitetura e Urbanismo - Universidade de São Paulo \\ jcskuhn@gmail.com
}

\section{Renato Cymbalista}

Faculdade de Arquitetura e Urbanismo - Universidade de São Paulo rcymbalista@hotmail.com

\begin{abstract}
Resumo
O presente artigo tem como objetivo observar as transformações envolvendo o Pátio do Colégio em São Paulo, no período entre 1889 e 1972, a partir de uma problemática central: o giro de $180^{\circ}$ - referente aos processos de construção, destruição e reconstrução do Pátio do Colégio - na posição pública a respeito daquele que é um dos espaços mais emblemáticos da cidade, local de seu nascimento e símbolo da espiritualidade colonial. Para isso, atenta aos agentes e grupos de interesse que incidiram sobre o Pátio do Colégio nessas nove décadas: lideranças políticas, intelectuais, imprensa e os padres da Companhia de Jesus e seus apoiadores.
\end{abstract}

\section{Palavras-Chave}

Pátio do Colégio, São Paulo, Companhia de Jesus, Secularização.

\begin{abstract}
This article aims to observe the transformations involving the Courtyard of the College in São Paulo, in the period between 1889 and 1972, from a central problem: turning $180^{\circ}$ - refers to the processes of construction, destruction and reconstruction of the Courtyard of the College - position in public about what is one of the most emblematic of the city, his birth place and emblem of colonial spirituality. For that, attentive to agents and interest groups that focused on the Patio do Colegio these nine decades: political leaders, intellectuals, the media and the priests of the Society of Jesus and his supporters.
\end{abstract}

Keywords 
Courtyard of the College, São Paulo, Society of Jesus, Secularization. 


\section{PÁTIO DO COLÉGIO: UM DESAFIO BIBLIOGRÁFICO.}

Em uma madrugada de tempestade de 1896, o teto da antiga e já abandonada igreja dos jesuítas em São Paulo ruiu. Tal evento potencializou um debate que já ocorria a respeito da destinação daquela parte tão especial da cidade, local preciso de seu nascimento. A decisão - possivelmente acelerando um processo já fadado a acontecer - foi pela destruição da igreja, sua substituição por um edifício administrativo e pelo alargamento da praça que já existia anteriormente na lateral do edifício. A igreja do Bom Jesus era o último remanescente do conjunto jesuítico que havia caracterizado o local de nascimento da cidade por muito tempo, e sua demolição permitiu que nesse mesmo local fosse construído "o primeiro conjunto urbanístico da capital [...] palco de manifestações cívicas" (Campos, 2002, p.08)

Em 1953, seis décadas depois, o terreno que se tornara propriedade do Estado após a expulsão dos jesuítas de São Paulo(1759) é devolvido à Companhia de Jesus e iniciam os processo de reconstrução do conjunto arquitetônico - escola e igreja - em um processo único de des-secularização do território.

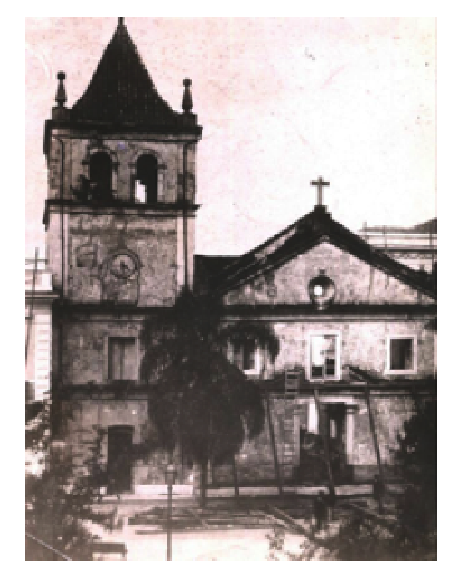

Figura 01 - Imagem do desabamento da igreja. Fonte: Jornal Estado de São Paulo de 14/03/1896

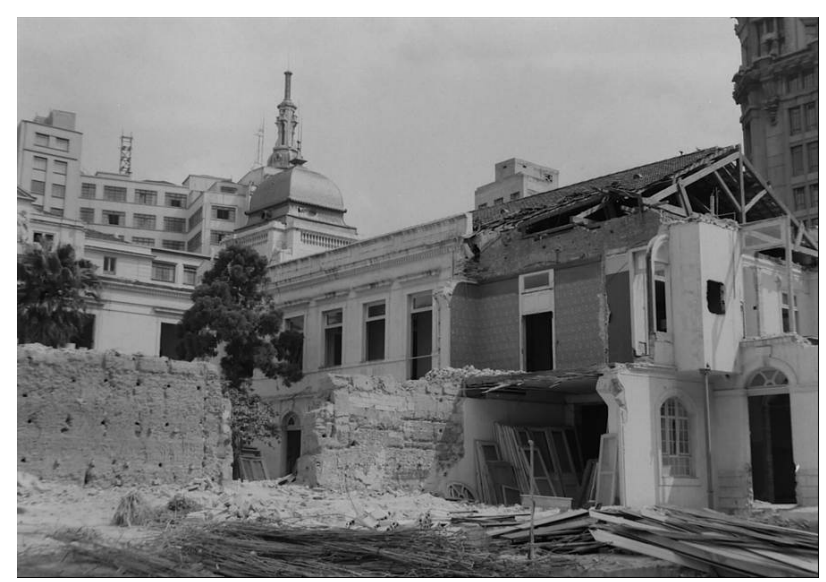

Figura 02 - Processo de demolição da Secretaria de Educação - antigo Pátio do Colégio - em 1953.

Fonte: Sebastião A. Ferreira - Arquivo Histórico de São Paulo

O valor simbólico do conjunto urbano e a intensidade das transformações relativas ao Pátio do Colégio fazem do lugar um território quase obrigatório na URBANA, V.6, no 8, jun.2014 - Dossiê: Cidade e Habitação na América Latina - CIEC/UNICAMP 
literatura sobre a cidade de São Paulo. Desde o primeiro historiador da Capitania de São Paulo, o padre beneditino Frei Gaspar da Madre de Deus, que escreveu em finais do século XVIII, a literatura reconhece o sítio do colégio dos jesuítas como ponto focal da colonização do interior do Brasil - ainda que se esforce em diluir a relevância dos padres da recém expulsa Companhia de Jesus no processo de colonização (Madre de Deus, 1975[1746], p. 119-141). Em consonância com Frei Gaspar, um conjunto de atores atenta prioritariamente para a função do Pátio como espaço originário da cidade (Ab Saber, 2004, pp.11-14; Kehl, 2005). A partir da década de 1930, quando muda a correlação de forças e a ideia do retorno do conjunto jesuíta volta a ser considerado, a historiografia tende também a uma mudança de tom, interessando-se mais pelo processo de agregação de atores sociais em torno do discurso da reconstrução e, frequentemente, denunciando o novo conjunto como simulacro, pastiche.

Autores como Lomonaco (2004), Toledo (2004), Donato (2008), atentam para as transformações que ocorreram na longa duração, evidenciando as sucessivas transformações e reocupações pelos quais passou o conjunto. Com o mérito de descreverem as complexas transformações físicas do Pátio, tais trabalhos rebaixam a relevância das tensões ou projetos alternativos.
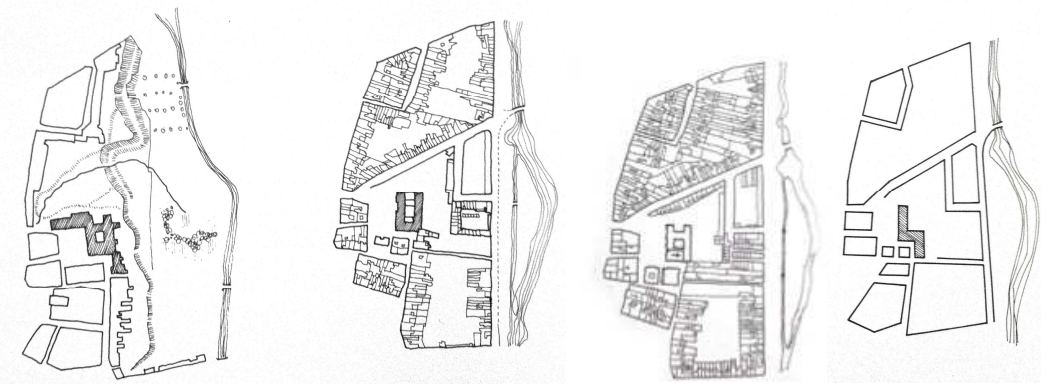

Figura 03 - O Pátio do Colégio em 1842, 1881 e 1897. Exemplo do interesse da historiografia paulistana pelas transformações do território nas longas durações, atribuindo maior interesse aos projetos edificados, e menor interesse às tensões e projetos alternativos.

Fonte: TOLEDO, São Paulo: três cidades em um século. São Paulo: Duas cidades,1983.

Solange Ferraz de Lima (2003) observa as transformações nas longas durações através das representações realizadas pelos cartões postais existentes em diversos períodos da história de São Paulo, onde observa-se não apenas as mudanças físicas do antigo pátio do colégio, mas descreve, de forma geral, a memória que a sociedade paulistana conservava vivade que naquele território existira o colégio dos jesuítas. Nestor Goulart Reis (2004) descreve cronologicamente todo o percurso do Pátio e observa desde a importância de sua localização no sítio escolhido pelo grupo URBANA, V.6, no 8, jun.2014 - Dossiê: Cidade e Habitação na América Latina - CIEC/UNICAMP 
de jesuítas, um local não apenas ideal para a educação da população local mas também, um ponto estratégico para a defesa da simples aldeia que ali fora criada, até sua total transformação após a expulsão da Companhia de Jesus do Brasil. O autor atenta principalmente para os personagens sociais laicos responsáveis pelas mudanças no território, mas não valoriza seus aspectos simbólicos ou espirituais. Um conjunto de trabalhos foi produzido como apoio intelectual ao processo de reconstrução, principalmente na década de 1970 (Dutra de Moraes, 1979; Salgado,1976). Luiz Octavio da Silva, em sua dissertação de mestrado (2005), trata o pátio do colégio como espaço inconcluso, propondo uma nova intervenção.

Hernani Donato atribui mais importância às tensões que ocorreram nos diferentes momentos, com uma aproximação cuidadosa dos acontecimentos em torno do Pátio desde de sua fundação até a inauguração do museu Anchieta em 1979. Ilumina alguns agentes menos destacados pelos autores acima, como os grupos de influência que defendiam a dimensão sagrada do lugar, e o imaginário popular que nunca desvinculou o sítio da Igreja. Sobre a década de 1890, afirma:"Os grandes decidiram. Os pequenos, os do povo, discutiram. A questão demolir ou restaurar empolgou São Paulo. A gritar em favor e contra a medida extrema levantou-se de variados setores e grupos." (Donato, 2004, p.223). O trecho citado demonstra a polarização da sociedade paulistana em relação aos destinos do templo semiarruinado após o fatídico temporal de 1896. Mais do que um debate intelectual, a fervorosa discussão em torno dos rumos do Pátio revela a relevância desse espaço para o imaginário paulistano em todas as classes e grupos sociais, como mostra também Moraes (1979). ${ }^{1}$

Alguns autores, como Levino Ponciano (2007),Maria Cristina Wolff (1996) e Candido Malta Campos (2002), revelaram-se mais interessados na construção do conjunto republicano no processo de modernização da cidade na passagem do império para a república. Lofego (2004), também interessado em um período específico, trata do debate no contexto das comemorações do IV Centenário. ${ }^{2}$

\footnotetext{
1 "debalde foram os protestos e as tentativas de conciliação do Brigadeiro Couto de Magalhães, de Dom Lino Deodato Rodrigues de Carvalho, do Prof. João Mendes de Almeida e tantos outros defensores da integridade e preservação do mais importante monumento histórico de São Paulo. Ninguém conseguiu demover o presidente Jorge Tibiriçá de seu infeliz propósito iconoclasta. Manteve-se intransigente, insensível aos apelos que lhe foram dirigidos, apesar do clamor público e do recurso à Justiça, interposto pela Cúria. Nada Valeu" (Moraes, 1979, p.53-54).

2 "Para Revista [a edição $\mathrm{n}^{\circ} 1$ da revista do museu da cidade de São Paulo ano 1994, que teve como tema os 40 anos do IV centenário da cidade de São Paulo] foi o traço de separação entre um antes e um depois'; pois a data de comemorações dos quatrocentos anos da fundação de São Paulo é , também, o ano em que São Paulo assume outra fisionomia, mudou de cara, e olhou-se e viu que iria deixar ser o que era. E, embora o que justificava a comemoração fossem os quatrocentos anos de fundação, 
Geraldo Dutra de Moraes (1979) que descreve com minúcias a situação arquitetônica e o patrimônio artístico existente no período da demolição da igreja na década de 1890, a aparência e estado da arquitetura de então, e relembra através de documentação e plantas e iconografias o que um dia fora o Pátio como local do sagrado - não chega a sistematizar as tensões vigentes no período.

Em que pese sua fundamental relevância para a recuperação da história das transformações do território do Pátio, a sistematização de fontes e de imagens, os trabalhos mencionados acima atribuem mais importância às forças vencedoras em cada período do que às tensões, disputas, projetos alternativos e formulações derrotadas. Tal foco nas transformações materiais efetivas não é de se estranhar, afinal trata-se de uma historiografia que tem como foco os sucessivos redesenhos da cidade. Por outro lado, se não atentarmos para os atritos, os projetos derrotados, o luto, a capacidade de agência e de articulação política dos segmentos inferiorizados (populares e eruditos), a reconstrução e a des-secularização do território ficam em grande medida inexplicados.

O presente artigo busca uma leitura dos processos de construção, destruição e reconstrução do Pátio "a contrapelo" dos processos de transformação material da cidade, atentando não apenas para os discursos vencedores, mas para a complexidade que envolveu tais transformações: debates, alternativas, transformações de discursos, derrotas que se revelaram temporárias (como a dos jesuítas) e vitórias que se revelaram também efêmeras (como a da secularização do espaço).

Não se trata de recuperar com simplicidade as rearticulações políticas, representando vitórias, derrotas e revanches de atores sociais estanques ou cristalizados no tempo, mas algo bem mais complicado. Todos os agentes em questão estiveram sujeitos às mudanças na conjuntura histórica, transformando seus discursos e alianças no decorrer do século XX, assimilando eventos como a reconstrução da identidade paulista após a crise de 1932; as comemorações do IV Centenário; a polarização social do período democrático (1945-1964); a ascensão dos militares ao poder após o golpe de 1964. Sem atentar para a incidência das conjunturas históricas sobre o discurso projetual, como compreender, por exemplo, as transformações nas proposições de Carlos Alberto Gomes Cardim Filho para o Pátio entre as décadas de 1950 e 1970, de uma proposta de reconstrução monumental do

nenhuma foto ou matéria é dedicada ao espaço símbolo da fundação da cidade: o Pátio do Colégio.." (Lofego, 2004, p.74) 
conjunto em linhas modernas, rumo a uma reprodução literal da espacialidade colonial (figuras 4 e 5$)$ ?

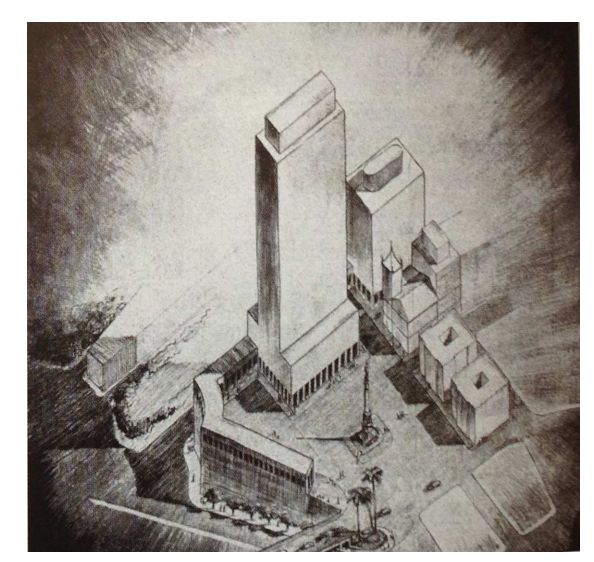

Figura 04 - Estudo Urbanístico para o Pátio do Colégio, de autoria de Carlos Alberto Gomes Cardim Filho. Fonte: Revista Acrópole n.151, p.180, nov.1950. (Ficher, 2005).

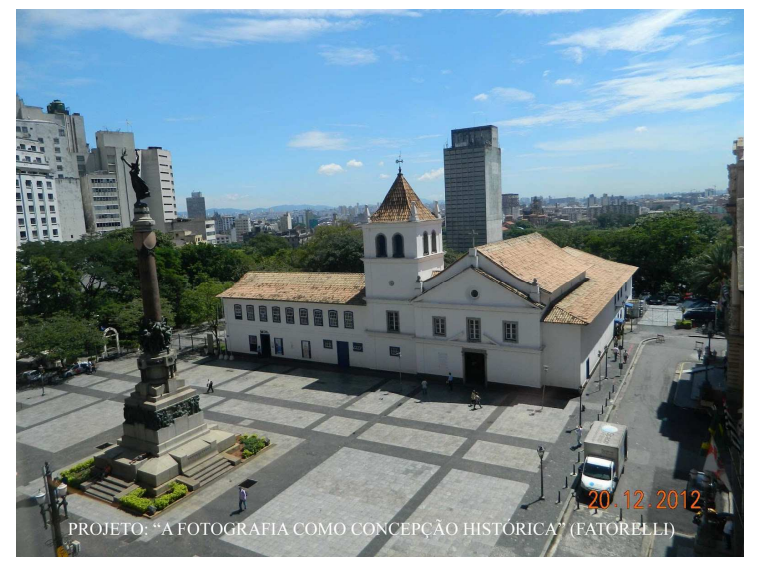

Figura 05 - Pátio do colégio - projeto de Carlos Alberto Gomes Cardim Filho, executado entre as décadas de 1950 e 1970.

Fonte: http://carlosfatorelli27013.blogspot.com.br

De uma forma geral, as tensões, resistências e alternativas às destruições e construções são tratadas apenas perifericamente pela historiografia. Por exemplo, autores simpáticos à reconstrução recuperaram as críticas e oposição à destruição da igreja no final do século $\mathrm{XIX}^{3}$, ou o caráter de sabotagem e abandono proposital por que passou a igreja antes da ruína de seu teto em $1896^{4}$. Sobre a manifestação dos grupos, Donato relata que no final do século XIX haviam dois grupos principais que abriram discussão em relação ao rumo que poderia ser dado a igreja: O governo que

\footnotetext{
3"Alvo da mávontade de muitosque o consideravamobsoleto,inestético, aolado do novo palácio, deixou de serconservado, murmurando-se atéquehaviaquemprocurasse, pormeio de goteiraspropositais,arruinar a segurança de suasparedesprincipais" SerafimLeite, apud Geraldo Dutra de Moraes (1979),p.53.

${ }^{4}$ Serafim Leite, História da Companhia de Jesus no Brasil. São Paulo. Loyola, vol. 10.
} 
tinha pressa pela demolição e o defensores pela reconstrução do sítio histórico. ${ }^{5}$ Maria Aparecida Lomonaco (2004), menciona o processo da Diocese contra o Estado, que havia incorporado a Igreja ao seu patrimônio em 1891. Aponta (mas não cita literalmente) as críticas de Prestes Maia e do historiador Affonso de Taunay, após a demolição, na ocasião da reconstrução da igreja na década de 1950. A mesma autora aponta as críticas de Benedito Lima de Toledo e Ulpiano Bezerra de Menezes ao que consideravam um simulacro do edifício original dos jesuítas (Lomonaco, 2004, pp. 121-140). Ou seja, é importante para o enriquecimento da discussão em torno das transformações no Pátio do Colégio, aprofundar e explorar os autores - e principalmente as fontes primárias, ainda largamente inexploradas - que atentaram para as tensões e articulações de agentes sociais em torno de discursos distintos em cada período histórico.

\section{Mudanças no discurso das elites paulistas e os grupos de políticos católicos}

As elites paulistas - tanto no Poder Público, como em partes da intelectualidade, como representantes de interesses econômicos - passaram por importantes transformações históricas, relacionando-se com as transformações políticas e econômicas ocorridas no Brasil e também por mudanças no cenário global, que significaram transformações em suas proposições espaciais para o Pátio do Colégio. A proposta de destruição do conjunto religioso, no final do século XIX, afinava-se com uma mentalidade liberal de uma elite que passava a dominar a cena econômica no Brasil, que enxergava-se como parte de uma elite internacional, esforçava-se por parecer europeia e afrancesada, o que pressupunha um espaço urbano equivalente (Rolnik, 1997, Campos, 2002). Nesse discurso, não havia lugar para a cidade colonial, emblema de um passado escravista e não-europeu que as elites paulistas se esforçavam em esconder (Cymbalista, 2002).

Se no final do século XIX o inimigo era a cidade colonial, o decorrer do século XX foi instalando novos desafios para as elites políticas e econômicas da cidade e do Estado de São Paulo. A organização operária de base anarquista e posteriormente com influências socialistas e comunistas aparece a partir da segunda década do século XX (Lopreato, 2000). O comunismo foi insistentemente associado ao ateísmo por seus opositores e a volta de um discurso religioso buscou agregar forças contra os

\footnotetext{
5 "Todos tinham pressa. Os defensores da permanência e da recuperação da igreja, pressa de que o Supremo decidisse a questão, decisão que por isso e por aquilo esperava-se favorável a Cúria. Quanto mais demorasse o resultado, mais derrúdo ficaria o templo. O governo tinha pressa pela necessidade em que se encontrava de acomodar a assembleia e pela agitação da opinião pública. Imprensa e porta-vozes governistas insistiam na absoluta necessidade de demolição." Donato, 2008.
} 
discursos de esquerda (Ferreira, 2005). Também a crise política no Brasil de 19301932 produziu impactos importantes nos discursos da elite paulista: se no final do século XIX a ideia era a de filiação em uma corrente liberal e modernizadora internacional, cresce a importância de afirmar-se como paulista, em contraponto a uma nacionalidade centralizadora que se construiu a partir da década de 1930 (Candido, 1987). Crescem, em importância, símbolos de uma regionalidade paulista, heroica, interiorizada e portanto "autêntica" (Abud, 1985).

As relações entre intelectuais e política no Brasil são tratadas por Sergio Miceli (2001) diante da extensa representação da missão dos intelectuais brasileiros, relacionado a suas origens sociais e posição na estrutura de poder, sobretudo no âmbito do Estado, reavaliando assim o lugar social desses intelectuais. O autor lista em seu texto diversos grupos de intelectuais, que tinham consigo a ideia de serem portadores especiais dos interesses da sociedade da época: os reformistas liberais do final do império, os positivistas republicanos, os modernistas e os críticos conservadores.

Faziam parte desse último grupo (os críticos conservadores),os intelectuais católicosresponsáveis pelo"rearmamento da Igreja Católica" ${ }^{6}$.Na década de 1920, quando a igreja se percebe diante da perda de privilégios edo crescente movimento de secularização da cultura,viu-se obrigada a expandir sua presença em áreas estratégicas do poder, ampliando sua relação de influência política através da criação de sistema de ensino, produção cultural e o enquadramento dos intelectuais que estivessem ligados a hierarquia da igreja.

Num ato de se afirmarem como modernos, não como os intelectuais paulistas ligados à Semana de 1922, mas portadores de um "modernismo espiritualista"(Miceli, p.128), esses intelectuais se apoiariam na ideia de uma tradição brasileira autêntica etradicionalista reorganizada por parte da igreja que buscava se reafirmar numa sociedade cada vez mais exposta aos pensamentos socialistascrescentes na época. Leigos ligados a esse movimento, como Alceu Amoroso Lima e Jackson de Figueiredo, encontraram espaço para difundir os interesse eclesiásticos no âmbito intelectual na criação da revista "A Ordem" (1921)e do Centro Dom Vital (1922) que no final da década de 20 conseguem se tornar uma força político-social contra o socialismo e todas as forças que ameaçavam a moral cristã.O

\footnotetext{
${ }^{6}$ Citada por Miceli em "Rearmamento da Igreja Católica", p. 127 e também explicada por RiolandoAzzi no texto "A igreja Católica no Brasil durante o Estado Novo (1937-1945)"no capitulo 5 - Fortalecimento da Igreja Católica, onde o autor coloca que a restauração da Igreja seria um "fortalecimento de uma presença mais expressiva do catolicismo romano na vida e na sociedade brasileira."
} 
discurso católico revelou-se em meados do século XX um instrumento importante em um cenário intelectual que refletia a polarização política, com comunistas e socialistas de um lado e seus opositores de outro lado.

Paulo de Damasco escreveu "A Igreja e o socialismo violento ou moderado" na revista A Ordem de 1938:

[...] Ora, em seu todo, o socialismo é taxativamente condenado pela Igreja, que o considera imoral, isto é, contrario ao direito natural e á moral cristã. Como peste mortal, uma seita de homens que se esforçam, sob os mais variados disfarces, por levar a cabo o desígnio de destruir os alicerces da sociedade civil (Leão XIII). Esse julgamento ainda não se modificou, em que pesem os vários aspectos que a doutrina socialista tem apresentado em suas aplicações, aqui e alhures, para insinuar-se cada vez mais no seio dos povos. Dando origem á doutrina da violência e da subversão completa de toda a ordem no mundo, que é o comunismo militante, o socialismo, pela voz dos seus mentores, diz ter evoluído, uma vez que transigiu quanto aos seus principais postulados - a luta de classes e a supressão da propriedade privada. [...] (DAMASCO, 1938)

O autordemonstrou a declarada luta contra o pensamento socialista, com o início da declarada adesão da Igreja Católica ao cenário político instaurado por Getúlio Vargas na década de 1930 quando o estado torna-se soberano perante a sociedade e acima de todo poder. O apoio da igreja católica ao projeto de Getúlio não apenas garantia lugar à uma igreja que se sentia ameaçada pela ideologia anarquista difundida desde o renascimento, mas auxiliavao "Estado Novo" de Vargas contrao pensamento comunista que se difundia nesse período. Assim, com a participação dos intelectuais conservadores aos quais se refere Miceli, o catolicismo volta a aproximarse do discurso do Estado, após o período da República Velha em que as elites políticas haviam se esforçado por separar as duas instâncias.

O poder desse discurso católico e conservador no desenho urbano das cidades brasileiras a partir da década de 1930 é frequentemente subavaliado. Este discurso, bastante operativo na prática - assim como uma poderosa articulação de atores sociais em torno dele - nos ajuda a explicar a reconstrução urbanística do Pátio do Colégio em São Paulo a partir da década de 1940. A igreja do Pátio do Colégio havia sido destruída no final da década de 1890 e substituída por um conjunto urbanístico laico e administrativo que enaltecia o poder do Estado. A igreja e o colégio dos jesuítas foram sendo recuperados no imaginário de São Paulo a partir da década de 1930 até serem reconstruídos entre as décadas de 1950 e 1970, como profecia que se auto realizava.

Analisada apenas sob a lógica do patrimônio histórico em senso estrito, a reconstrução da Igreja dos Jesuítas chega a ser tratada como ato de mau URBANA, V.6, no 8, jun.2014 - Dossiê: Cidade e Habitação na América Latina - CIEC/UNICAMP 
gosto,pastiche ou simulacro. Se, por outro lado, analisarmos essa reconstrução a partir da estruturação do discurso católico e conservador - sempre em contraponto com sua antítese, o socialismo - emerge um cenário bem mais complexo. Percebemos o quão católica foi a reconstrução da Igreja. Percebemos também o elo católico ativo e operacional no interior das elites políticas paulistas que sempre se esforçaram em mostrar-se liberais e afeitas às forças do progresso.

A ASIA (Antiqui Societatis Iesus Alumni) ou Associação do antigos alunos jesuítas,que emSão Paulo foi fundado em $1932^{7}$, foide igual importância nessa relação de disputa de poder e de reafirmação dos valores tradicionais católicos. Grupo tradicional nas escolas dos jesuítas em todo mundo, esses ex-alunos participavam de reuniões periódicas sempre acompanhados pela comunidade jesuítica sendo reflexo nesse movimento realizado pelo igreja nesse período, onde tinham como objetivo continuar a formação cristã e Inaciana perpetuando assima memória da Companhia de Jesus.

Em São Paulo,o grupo composto por notáveis ex-alunos do Colégio São Luis fundado em Itu em 1867 e posteriormente transferido em 1918para aAvenida Paulista $^{8}$ - participou ativamente dos movimentos em prol da devolução do terreno do Pátio do Colégio e posteriormente da sua reconstrução através de Campanhas de gratidão onde reuniam as mais importantes personalidades da sociedade paulistana contribuindo também com interesses eclesiásticos da época.

Em 1941, Jose Marianno, ${ }^{9} \mathrm{em}$ seu discurso no Rotary Club de São Paulo, foi um dos primeiros a colocar no debate público a reconstrução do antigo Pátio do Colégio. Marianno não apenas trata a reconstrução na chave patrimonial, mas também na percepção do sagrado, reforçando o elo entre nação e a religião católica:

Dentro de 13 anos São Paulo comemorará o $4^{\circ}$ centenário de sua fundação, seria um ato da mais alta significação cultural a reconstituição integral da igreja dos jesuítas, e uma ala do antigo colégio, exatamente no sítio em que ela existia, de modo a ser novamente, rezada a primeira missa no planalto de Piratininga o pequeno oratório de "pau e barro" constituído pelos índios para Joseph de Anchieta. São Paulo tem uma dívida sagrada a resgatar com a

\footnotetext{
${ }^{7}$ Fonte na seção de antigos alunos do site do Colégio São Luis em São Paulo: http://www.saoluis.org

${ }^{8}$ Fontes disponíveis no site: http://www.saoluis.org

${ }^{9}$ José Marianno foi adepto da corrente tradicionalista defendida também por Ricardo Severo que de acordo com Joana Mello (2006) e Maria Lucia Bressan Pinheiro (2011), estavam engajados na campanha em defesa da arquitetura tradicional no Brasil nas primeiras décadas do século XX. Defendiam a arquitetura colonial brasileira como uma arquitetura original.
} 
Companhia de Jesus. O momento é chegado. (LIMA, 2003 apud CARDIM FILHO, 1975)

Preocupado com os rumos que se desenvolviam em torno da destinação do terreno do antigo Colégio dos Jesuítas, o grupo de antigos alunos organizou, em 1953, o Movimento Pró-Igreja do Pátio do Colégio,com o propósito de "reerguer quando possível, no estilo antigo, os monumentos primitivos sobre os alicerces existentes" (DONATO,2008). Uma reportagem no jornal Folha da Noite de 23 de Outubro de 1953, demonstra uma das primeiras ações oficiais no processo de devolução do terreno do Pátio do Colégio, que pertencia naquele momento ao estado de São Paulo. O projeto de lei do deputado Yukishigue Tamura - ex-aluno jesuíta fora aprovado mesmo sendo contestado por historiadores que alegavam a devolução uma decisão equivocada:

Nos fins de 1953 a Assembleia Legislativa de São Paulo, aprovava projeto de Lei do deputado YukishigueTamura, fez pertence a Companhia de Jesus, do mais valorizado terreno de São Paulo, do quinhão maior do patrimônio histórico da cidade, isto é, da área destinada ao Pátio do Colégio, onde e existiram a cabana e o primeiro estabelecimento de ensino de Anchieta. [...]Historiadores consultados pela reportagem são de opinião que o projeto Tamura foi aprovado de afogadilho e transformações na Lei sem muito estudo, pois a doação representou verdadeiro atentado contra nosso patrimônio histórico.(RECOMENDADA...,1956)

Duas personalidades em destaque nas realizações dos interesse da Companhia de Jesus e da frente tradicionalista católica do período presentes em questões políticas do estado, foram Altino Arantes e Cesar Salgado. Presidente nacional da Associação de Ex-alunos jesuítas, Altino Arantes teve sua formação acadêmica na Faculdade de Direito do Largo de São Francisco (1895), foi membro do Partido Republicano Paulista (PRP) sendo presidente do Estado de São Paulo de 1916 a 1920. Como intelectual foi membro da Academia Paulista de Letras e presidente efetivo do Instituto Histórico e Geográfico de São Paulo e José Augusto Cesar Salgado, também Bacharel pela Faculdade de Direito do Largo de São Francisco (1917), tornou-se Promotor Público nas comarcas de Atibaia, Socorro e, por fim, São Paulo. Ambos estavam à frente das ações jesuíticas nesse período, não apenas como figuras políticas mas como representantes da espiritualidade jesuíta, como demonstram os jornais da época e representavam, com seus poderes, os interesses de ação católica e jesuíta. 
Podemos observar o movimento gerado por essas figuras notáveis, ex-alunos dos jesuítas, nas campanhas voltadas para a reconstrução do Pátio do Colégio e outras edificações da Companhia de Jesus. Em sua justificativapara o inicio da campanha pela reconstrução da Igreja, Altino Arantes destacou ao jornal Folha da noite a importância do grupo dos ex-alunos:

A ideia surgiu durante as comemorações do IV Centenário, nas reuniões da Associação dos Antigos Alunos Jesuítas, pensando no trabalho prestado pelos jesuítas aos nossos pais e, notadamente no papel preponderante por eles desenvolvidos na fundação da cidade, a sua formação formal e intelectual. Não poderíamos ficar imóveis. (LANÇADA...,1955)

O grupo do Movimento Pró-Igreja, além de grande divulgação nos meios de comunicação mais relevantes da época, promoviacoquetéis e jantares, buscando a adesão de "paulistanos de boa vontade ${ }^{10} \mathrm{com}$ valores de patriotismo que pudessem apoiar a causa e levantar dinheiro necessário para a reconstrução do conjunto jesuítico. Tinha como principal orador Altino Arantes, que trazia em seus discursos um tom nacionalista e uma nostalgia histórica por São Paulo, convidando as mais ilustres personalidades políticas e sociais e assim angariando não apenas adeptos para as doações monetárias mas também participantes para as comissões e frentes de trabalho.

Dividindo-se em equipes, o movimento Pró-Igreja estava atento aos acontecimentos em torno do Pátio do colégio, criando assim uma comissão de preservação das relíquias do Pátio do Colégio. Quando foi anunciada a demolição da Secretaria de Educação para dar lugar ao conjunto reconstruído, o grupo se empenhou em reconhecer e recolher possíveis relíquias do antigo colégio assumindo para a Companhia de Jesus o papel de herdeiro espiritual do próprio Pátio do Colégio.

Esses bens recolhidos, assim como outros adquiridos através da diocese no período da demolição da igreja em $1896^{11}$ que se encontravam em Itu até o

\footnotetext{
${ }^{10} \mathrm{O}$ termo "Paulistanos de boa vontade" era constantemente utilizado por Altino Atantes em seus discursos que buscavam adesões de novos apoiadores da Campanha de Gratidão aos fundadores de São Paulo.
}

${ }^{11}$ Reportagem sobre o relatório da demolição da igreja Bom Jesus do Pátio do Colégio escrita pelo Dr. Antônio Dino da Costa Bueno, onde cita a retirada de relíquias antes da demolição em 1896. Jornal "A Gazeta" de 03/09/1949. " [...]Examinando o edifício e reconhecida a impossibilidade de se conservar sem risco publico, ficou assentado entre o governo e o bispo diocesano demolir-se a parte arruinada, remover os objetos do culto, as obras de ornamentação dos altares e púlpitos para a sacristia da Igreja de São Pedro, sita ao Largo da Sé, onde devidamente colocados em ordem e numerados, aguardassem, por parte da autoridade eclesiástica, idêntica aplicação em tempo oportuno.[...] Foram, então iniciados 
momento, serviriam posteriormente para restauro das relíquias de Anchieta - como o crucifixo de Anchieta, restaurado com madeira extraída da demolição da Secretaria deEducação - e para a restauração do colégio, além de compor o acervo do museu de Anchieta.

O Professor José de Vilhena Nunes, membro da comissão executiva Pró-Igreja e ex-aluno jesuíta, organizou uma exposiçãocom as relíquias de Anchieta período antes da reconstrução do Pátio do Colégio:

[...]Figuram também nesta mostra varias alfaias, como sejam um genuflexório, uma mesa, um armário, estantes de missal, retábulos para afixação de avisos, cruzes, quadros, etc. Que, embora não sejam objetos de uso do venerável Padre Anchieta existentes outrora no consistório da Igreja do Pateo do Colégio. Esse soalho é precioso, por ter sido testemunha das virtudes e vida venerável Anchieta e palmilhado pelos seus pés. Quando se deu a destruição da Igreja, foram adquiridos pelo então Reitor do Colégios dos Jesuítas, Padre Mantero, em 1896, e levadas para Itu , 24 taboas de canela preta, onde foram aproveitadas pelo Irmão leigos Frateli que delas fez as ditas alfaias.(UMA VALIOSA...1955.)

As discussões em torno do Pátio do Colégio giravamnão apenas como uma forma de justiça á Companhia de Jesus, mas também, como defesa da fé católica na construção da identidade nacional.

Quando observamos esse movimento de profundo civismo que a "Campanha de Gratidão aos Fundadores de São Paulo"; quando contemplamos o esforço, a diligencia dos seus patronos, lembramo-nos de uma frase lapidar de Tobias Barreto: "A gratidão é a virtude da posteridade". Varões ilustres pela sabedoria e pelas estirpes a quem pertencem Altino Arantes e J.A. Cesar Salgado, para citarmos apenas dois nomes, estão empenhados nessa campanha de gratidão, estão pagando nossas dívidas aos heroicos, aos abnegados fundadores de São Paulo.A melhor maneira de se cultuar o passado é divulgar o ensino da história, estabelecendo relações entre o presente e o passado, entre o dia de hoje e o de Ontem. Um povo que conhece a sua história, que cultua os seus heróis, seus santos e seus mártires, um povo que vai para a frente sob a inspiração do passado, um povo que encontra nos exemplos antigos coragem e estimulo para os seus empreendimentos futuros é um povo vitorioso, um povo invencível. [...]A Campanha de Gratidão tem o alto valor de fazer reviver o culto à tradição trazendo ao conhecimento dos moços as figuras daqueles homens formidáveis [...] fundaram a nossa cidade, a maioria das cidades brasileiras, plasmando

os trabalhos de exumação, precedendo aos de demolição e sendo abertas, e sendo abertas as sepulturas existentes no corpo da Igreja; uma em frente ao segundo altar lateral à direita da capela mor, outra em frente ao primeiro e ainda outra em frente ao primeiro altar lateral à esquerda.[...] 
uma civilização cristã e democrática da qual tanto nos orgulhamos. Aos dirigentes dessa benemérita campanha apresentamos as nossa congratulações fazendo nossas estas palavras de Antístenes: "O reconhecimento é a memória do coração.(AMIGOS..., 1955)

Portanto, podemos observar que o movimento realizado pelo grupo de antigos alunos e religiosos da Companhia de Jesus, pouco tratado pela bibliografia geral sobre o processo de reconstrução do Pátio do Colégio, não se encerra apenas na discussão entre o próprio grupo e muito menos os coloca como parte passiva de todo o processo, mas rebate na construção de um imaginário sagrado, de uma identidade histórica nacionalista e na concretização de elementos visíveis no redesenho, arquitetônico e urbanístico, desse importante símbolo da cidade de São Paulo.

\section{Considerações Finais}

As tensões, resistências e alternativas às destruições e construções que são tratadas em torno do Pátio do Colégio são, de forma geral, observadas perifericamente pela historiografia geral e pela historiografia em arquitetura e urbanismo, colocando os grupos de intelectuais e religiosos jesuítas como meros espectadores no processo de reconquista do território do colégio e da igreja Bom Jesus.

Na busca de uma leitura desses processos, atentando não apenas para os discursos vencedores mas para a complexidade que envolveu tais transformações, pode-se observar um desafio intelectual provocado por esses grupos não tão expostos que possui rebatimentos urbanístico e arquitetônicos. Acredita-se, com isso, ser possível enriquecer a historiografia sobre esse território, matizando as abordagens que atribui maior relevância às transformações físicas, revelando que estas só ocorreram por reconfigurações sucessivas de correlações de forças e, bem entendido, as legitimaram.

Portanto, analisar a reconstrução da igreja e do Pátio do Colégio sob a lógica do conservadorismo católico e mais especificamente a do grupo dos antigos alunos jesuítas, permite adensar a visão sobre este e outros processos. Principalmente, permite adentrar no universo de valores de grupos específicos das elites políticas paulistas, que não viam como incompatíveis valores como a religião, o liberalismo e o progresso econômico. As formas específicas de recuperação da narrativa histórica, e de seus espaços, que ocorreram em São Paulo na segunda metade do século XX são em grande medida tributárias desses valores. 


\section{Referencias}

AB SABER, Aziz. São Paulo: Espaços Entreveros. São Paulo: Edusp/Imprensa Oficial, 2004.

ABUD, Kátia $M$. O sangue intimorato e as nobilíssimas tradições: a construção de um símbolo paulista: o bandeirante. Tese de doutorado, FFLCH-USP, 1985.

AZZI, Riolando. A Igreja Católica no Brasil durante o Estado Novo. Síntese Revista de Filosofia Volume 7, número 19, Rio de Janeiro. 1980.

BRUNO, Ernani da Silva. História e tradições da cidade de São Paulo. Rio de Janeiro: José Olympio, 1953.

BRUAND, Yves. Arquitetura contemporânea no Brasil. São Paulo: Ed. Perspectiva, 2010.

CANDIDO, Antônio. A educação pela noite e outros ensaios. São Paulo: Ática, 1989

CAMPOS, Candido Malta. Os rumos da cidade - urbanismo e modernização em São Paulo. São Paulo: SENAC, 2002.

CYMBALISTA, R. Cidade dos vivos: arquitetura e atitudes perante a morte nos cemitérios paulistas. SP:Annablume, 2002.

DONATO, Hernani. Pateo do Collegio: Coração de São Paulo. São Paulo: Ed. Loyola, 2008.

FERREIRA, Roberto Martins. Organização e poder: análise do discurso anticomunista do Exército Brasileiro. São Paulo: Annablume,2005.

FICHER, Sylvia. Os arquitetos da Poli: ensino e profissão em São Paulo. São Paulo: Edusp, 2005.

KEHL, Luis Augusto Bicalho. Simbolismo e Profecia na Fundação de São Paulo. ( A casa de Piratininga). São Paulo: Ed. Terceiro Nome. 2005.

LEITE, Serafim. História da Companhia de Jesus no Brasil. Lisboa: Portugalia; Rio de Janeiro: Instituto Nacional do Livro, 1938-1950. 10 v. il.

LIMA, Solange Ferraz de. Pátio do Colégio, Largo do Palácio. São Paulo: Anais do museu paulista, 2003.

LOFEGO, Silvio Luiz. IV Centenário da cidade de São Paulo. Uma cidade entre o passado e o futuro. São Paulo: Ed. AnnaBlume. 2004.

LOMONACO,Maria Aparecida "O Pátio do Colégio". In: Eduardo Bueno (org), Os nascimentos de São Paulo. Rio de Janeiro: Ediouro, 2004 
LOPREATO, Christina Roquette: "O espírito da revolta: a greve geral anarquista de 1917" São Paulo: Annablume,2000.

MADRE DE DEUS, Frei Gaspar. Memórias para a História da Capitania de São Vicente. Belo Horizonte: Itatiaia/São Paulo, Edusp, 1975 [1746].

MARX, Murillo. Nosso chão, do sagrado ao profano. São Paulo: Edusp, 1989.

MELLO, Joana. Da arqueologia portuguesa à arquitetura brasileira. São Paulo: Revista do Instituto de Estudos Brasileiros - no 43, 2006.

MICELI, Sergio. Intelectuais à brasileira. São Paulo: Companhia das Letras, 2001. MORAES, Geraldo Dutra de. A Igreja e o colégio dos Jesuítas de São Paulo. São Paulo: Prefeitura do Município de São Paulo. 1979.

MORSE, Richard M. Formação Histórica de São Paulo (de comunidade a Metrópole). São Paulo: Difusão Européia do Livro, 1970.

PINHEIRO, Maria Lucia Bressan. Neocolonial, modernismo e preservação do patrimônio no debate cultural dos anos de 1920 no Brasil. São Paulo: Edusp,2011.

PONCIANO, Levino. Todos os centros da Paulicéia. São Paulo: SENAC, 2007, pp.60-61.

REIS FILHO, Nestor Goulart. São Paulo: vila, cidade, metrópole. São Paulo: Via das Artes, 2004.

ROLNIK, Raquel. A cidade e a lei. São Paulo: Studio Nobel/FAPESP, 1997.

SALGADO, César. O Pátio do Colégio - História de uma Igreja e de uma Escola. São Paulo. Gráfica Municipal de São Paulo, 1976.

SAMPAIO, Teodoro. A fundação da cidade de São Paulo. São Paulo, Revista do Instituto Histórico Geográfico de São Paulo, vol. 10, 1905.

SILVA, Luis Octavio de Faria e. Pátio do Colégio: 0 centro de tradicional Paulistano. São Paulo: Fapesp. 2005.

TOLEDO, Benedito Lima de. SÃo PAULO - Três cidades em um século - $3^{a}$ ed. São Paulo: Cosac Naify - Ed. Duas cidades - 2004.

WOLFF, Maria Cristina. Bem Morar em São Paulo, 1880-1910: Ramos de Azevedo e os modelos europeus in Anais do Museu Paulista, v. 4. São Paulo, Museu Paulista, 1999.

\section{Periódicos}

A DEMOLIÇÃO da igreja do colégio. Jornal A Gazeta, São Paulo. 03/09/1949. p.8 AMIGOS da cidade - O Pátio do Colégio. Jornal Diario \& Comércio. 25/09/1955. 
DUAS paredes intactas de pau a pique e ripas de coqueiro! Jornal A Gazeta, São Paulo, 18/11/1953. p.24

LANÇADA por antigos alunos jesuítas a campanha de gratidão, Jornal Folha da Noite, São Paulo, 24/08/1955. p.1.

PICKEL, D. Bento José. As madeiras do Pátio do Colégio. Jornal A Gazeta. $7 / 10 / 1954$.

RECOMENDADA a reintegração ao patrimônio do estado do terreno doado aos jesuítas. Jornal Folha da noite. 23/10/1956.

UMA VALIOSA exposição Anchietana no Pátio do Colégio. Jornal A Gazeta. 06/06/1955. 